\title{
Obesity and eating disorders: Cognitive aspects of food preference and food aversion
}

\author{
ADAM DREWNOWSKI \\ University of Michigan, Ann Arbor, Michigan
}

\begin{abstract}
Food choices in obesity and eating disorders are influenced by a number of metabolic, psychological, and sociocultural variables. Whereas obese patients often seek out fat-rich foods, anorectic women tend to avoid them. Clinical studies suggest that cravings for palatable sweet desserts have a metabolic basis and may involve alterations in the endogenous opioid peptide system. Food preferences may also be influenced by metabolic status of the organism and the prior history of "yo-yo" dieting. Sensory responsiveness to sugar/fat mixtures may be further modified by subjects' attitudes and beliefs regarding the nutritional value of foods, notably those rich in sugars and fats. Together with changing normative beliefs, attitudes toward calorie-dense foods can modulate the hedonic taste response and influence the patterns of food selection.
\end{abstract}

Obesity and eating disorders such as anorexia and bulimia nervosa represent disturbances in the regulation of food intake as well as abnormalities in diet selection. Although most research efforts in this area have focused on physiology, endocrinology, and metabolism, cognitive functions are involved as well. Food preferences and aversions in obesity and eating disorders are often subject to cognitive bias; they are strongly influenced by attitudes and beliefs related to health, dieting, and body weight.

Human obesity is thought to represent an interaction between genetic predisposition and exposure to environmental variables, including diet. Experts agree that genetic, biological, psychological, and sociocultural factors all contribute in different ways to the development and maintenance of the obese state (Diet and health, 1989; The Surgeon General's report, 1988). Although the precise role of diet is still unclear, macronutrient composition of the diet is likely to be among the key variables. Studies of animals indicate that a high dietary fat-to-carbohydrate ratio promotes body fat deposition and weight gain. Whereas excess carbohydrate calories are dissipated as heat, excess fat calories are more likely to be deposited as body fat (Flatt, Ravussin, Acheson, \& Jequier, 1985; Schwartz, Ravussin, Massari, O'Connell, \& Robbins, 1985). Consequently, selection of high-fat foods by humans is likely to be an important factor in the development of human obesity (Tuorila \& Pangborn, 1988).

The study of taste and sensory preferences for high-fat foods has thus acquired new importance in obesity research. There is preliminary evidence that sensory responsiveness profiles to sugar/fat mixtures may help distinguish between different subgroups of obese individuals. Such subgroups may be characterized by familial risk of

Correspondence should be addressed to Adam Drewnowski, School of Public Health M-5170, University of Michigan, Ann Arbor, MI 48109-2029. obesity, early age of onset, or past attempts at weight reduction. There is evidence, for example, that taste and food preferences may be modified by past history of weight loss and weight regain. Animal data indicate that preferences for dietary fats may increase after repeated cycles of weight loss and weight regain (Reed, Contreras, Maggio, Greenwood, \& Rodin, 1988). Although human data are scarce, there is preliminary evidence that obese weight cyclers show elevated sensory response to sweet fat-rich foods. Dietary intake data further indicate that obese women do not consume excess calories-but that their diet may be richer in fat.

\section{SENSORY STUDIES}

Sensory studies of sweet foods distinguish between judgments of sweetness intensity and hedonic preference ratings (Moskowitz, Kluter, Westerling, \& Jacobs, 1974). Although intensity judgments follow the log of sucrose concentration, acceptability ratings for sweetness can be highly variable. Some subjects prefer, but others dislike, sugar solutions of increasing sweetness intensity. The average response typically follows an inverted-U shape as preferences first increase with increasing sugar concentration, reaching a maximum or breakpoint at around $8 \%-10 \%$ sucrose (Moskowitz et al., 1974).

However, taste preferences for sweet solutions are not a good index of preference for sweet high-calorie foods. Most "sweets" and other desserts are solids rather than liquids, and they often contain fat as a major ingredient and the principal source of calories. The acceptability of such foods is determined by both their sugar and their fat content (Drewnowski, 1987). Accordingly, the current research emphasis is on the sensory contributions of dietary fat to food acceptance. Instead of sweet solutions, researchers now use such realistic stimuli as milkshakes, cream cheese, cake frostings, or ice cream (Drewnowski, Bellisle, Aimez, \& Remy, 1987; Drewnowski, Brunzell, 
Sande, Iverius, \& Greenwood, 1985; Drewnowski \& Greenwood,_1983; Moskowitz et al., 1974).

Studies of sensory acceptability of sugar/fat mixtures (Drewnowski et al., 1985) have shown that subjects' preferences for sugar as opposed to fat may help us to discriminate between clinical populations of women patients at extremes of body weight (Drewnowski, Halmi, Pierce, Gibbs, \& Smith, 1987; Drewnowski et al., 1985). In a series of sensory evaluations in which 20 different mixtures of milk, cream, and sugar were used, groups of obese and anorectic patients showed that obese women preferred stimuli that were rich in fat but relatively low in sugar. In contrast, anorectic women liked sweet tastes, but their preferences for the oral sensation of dietary fat were reduced.

\section{METABOLIC FACTORS}

Food preferences and food cravings are sometimes thought to be triggered by physiological or metabolic events. For example, obese people are sometimes said to crave carbohydrates because of a deficiency in central serotonin metabolism (Wurtman, 1984). Selective consumption of carbohydrate-rich snacks is said to restore serotonin metabolism, promote satiety, and relieve depression and fatigue. Selective appetite for carbohydrate-rich snacks is thus viewed as being induced by central metabolic events.

However, anecdotal reports and clinical observations consistently show that the most common targets of food cravings are such foods as chocolate candy, cakes, and ice cream. Even studies on carbohydrate craving used such foods as chocolate (Snickers and M\&Ms), chocolate cupcakes, chocolate chip cookies, cakes, frozen pastries, and other desserts (Paykel, Mueller, \& de la Vergne, 1973; Rosenthal, Genhart, Jacobsen, Skwerer, \& Wehr, 1987). Such foods are, for the most part, sweet and are composed largely of two ingredients: sugar and fat. Clearly, the sensory response to food is an important contributing variable.

The involvement of opioid peptides-pleasureenhancing molecules manufactured by the brain-may provide an explanation for some of the food cravings manifested by obese and normal-weight binge eaters. In studies of rats and mice (Blass, 1987), intakes of sugar and fat have been linked with the endogenous opioid peptide system. Recent clinical studies have shown that sensory preferences for sugar/fat mixtures and the consumption of sweets are reduced by infusions of opioid antagonist naloxone (Drewnowski, Gosnell, Kiahn, \& Canum, 1989). The greatest reduction occurred in a group of women subjects identified as binge eaters.

\section{TASTE AND FOOD PREFERENCES}

Preferences for sweet, high-calorie foods are thought to play a major role in the development of human obesity. However, enhanced taste responsiveness to sugar/fat mixtures does not necessarily lead to overeating of all sweet desserts. Although taste factors are undoubtedly important in determining food acceptance, attitudes toward health, body weight, and dieting often override physiological and metabolic signals. In other words, taste is often tempered by experience (Drewnowski, 1983).

Enhanced pleasure response need not be a characteristic of all human obesity. Although in studies done with laboratory rats consumption has been used as an index of palatability, more recent studies have suggested that diet palatability and hyperphagia are not necessarily linked (Sclafani, 1985). Similarly, studies done with humans have suggested that taste preferences alone are not a good index of food consumption (Mattes, 1985). People do not always eat more of palatable than of unpalatable foods, and there are many intervening steps between taste responsiveness, food acceptability, and food consumption. A distinction should also be made between short-term food intake, typically assessed with a single meal consumed under laboratory conditions, and the habitual long-term patterns of food consumption in real life.

Preferences for sugar/fat mixtures may be modulated by previous experience, or they may be contingent on attitudinal or social variables, including attitudes toward body weight and dieting. Past experience may include positive postingestional consequences; the provision of calories is itself reinforcing to a hungry organism. In contrast, the aversion to fats in eating disorders may be linked to bouts of nausea and vomiting. Fats absorb the smells and odors of foods and provide a salient target of food aversion both in pregnancy and among cancer patients undergoing chemotherapy (Midkiff \& Bernstein, 1985).

\section{FOOD CHOICES AND FOOD CONSUMPTION}

What foods do overweight people say they like to eat? In a large study of U.S. Army personnel, Meiselman, Waterman, and Symington (1974) showed that overweight people selected red meat dishes rather than desserts. Preliminary data from several hundred obese patients confirm that self-reported food preferences of obese males typically include steaks and roasts, hamburgers, french fries, pizza, and ice cream, whereas obese women list bread, cake, cookies, ice cream, chocolate, pies, and other desserts.

There is no evidence at present that the diet of overweight people is rich in sugars. In epidemiological studies, an inverse correlation between sugar consumption and the degree of being overweight has repeatedly been observed. In a nationwide survey of almost 1,000 adolescents (5-18 years old) no significant link was found between body fatness and self-reported intakes of sweet snacks (Morgan, Johnson, \& Stampley, 1983). Data from the Ten-State Nutrition Survey showed no relationship between triceps skinfold of teenagers and reported intakes of sugar-containing foods, including jams, honey, candies, and soft drinks (Garn, Solomon, \& Cole, 1980).

On the contrary, there is increasing evidence that the diet of obese persons is relatively rich in fat. Although obese women do not consume substantially more calories 
than lean women do, their fat-to-carbohydrate ratio is substantially higher. Similarly, in several dietary studies, obese men have been observed to select a diet relatively rich in fat.

Preferences for dietary fat may be modified by the perception that fat is an unhealthy source of excess calories. Some obese and most eating-disorder patients are characterized by a high level of dietary restraint. The obese diet and evidently fail; anorectics diet and succeed. Anorexia nervosa involves extreme caloric restriction and a severe loss of body weight. Bulimia nervosa is characterized by frequent eating binges that may be countered by fasting, purging, or self-induced vomiting to lose weight (Drewnowski, Halmi, Pierce, Gibbs, \& Smith, 1987).

Unlike obese women, anorectic women show an aversion toward dietary fats. According to some reports, anorectic women are willing to eat vegetables, lettuce, fresh fruit, cheese, and sometimes eggs, but they are disgusted by milk and meat (Russell, 1967). In attitudinal studies, it has been confirmed that anorectic women report liking only foods that they also view as nutritious and low in calories (Drewnowski, Pierce, \& Halmi, 1988). Among the top food choices were salads, vegetables, and fresh fruit. In a study based on 24-h food recalls, Beaumont and Chambers (1981) reported that anorectic patients ate a normal amount of carbohydrate but significantly less fat than did normal-weight controls.

Food preferences in bulimia appear to resemble those of some obese women. Clinical observations (Russell, 1979) have suggested that typical binge foods are bread, cakes, chocolate, yogurt, or cottage cheese. The patients ate up to $7 \mathrm{lb}$ of food, and the magnitude of an eating binge was estimated at $15,000-20,000 \mathrm{kcal}$. The chief binge foods included ice cream, bread, candy, doughnuts, soft drinks, salads, sandwiches, cookies, popcorn, milk, cheese, and cereal (Abraham \& Beumont, 1982; Rosen, Leitenberg, Fisher, \& Khazam, 1986). Bulimic patients monitored in a hospital setting mostly consumed doughnuts, pies, sandwiches, chocolate candy, and carbonated beverages. In contrast, eating bouts not classified as binges included salads, vegetables, fruit, and diet soft drinks. According to most reports, eating binges typically included high-fat, moderate-carbohydrate, and low-protein foods.

\section{CONCLUSIONS}

Taste responsiveness plays a central role in mediating the connection between metabolic status, food acceptance, and food consumption. On one hand, central and peripheral manipulations of metabolic status are reported to result in short-term changes in taste responsiveness and may be responsible for selected food cravings. On the other hand, taste responsiveness modified by experience is one of the key factors that determine food acceptance. It is likely to influence habitual food consumption. Further research needs to deal with the ways in which biological, psycho- logical, and sociocultural variables determine the regulation of feeding in human obesity and eating disorders.

\section{REFERENCES}

Abraham, S. F., \& Beumont, P. J. V. (1982). How patients describe bulimia or binge eating. Psychological Medicine, 12, 625-635.

Beumont, P. J. V., \& Chambers, T. L. (1981). The diet composition and nutritional knowledge of patients with anorexia nervosa. Journal of Human Nutrition, 35, 265-273.

BlASS, E. M. (1987). Opioids, sugar and the inherent taste of sweet: Broad motivational implications. In J. Dobbing (Ed.), Sweetness (ILSINutrition Foundation Symposium). Berlin: Springer.

Diet and health (1989). (Report of the Food and Nutrition Board, National Academy of Sciences.) Washington, DC: National Academy Press.

Drewnowski, A. (1983). Cognitive structure in obesity and dieting. In M. R. C. Greenwood (Ed.), Obesity: Contemporary issues in clinical nutrition (pp. 87-101). New York: Churchill Livingstone.

Drewnowski, A. (1987). Fats and food texture: Sensory and hedonic evaluations. In H. R. Moskowitz (Ed.), Food texture (pp. 217-250). New York: Marcel Dekker.

Drewnowskı, A., Bellisle, F., Aimez, P., \& Remy, B. (1987). Taste and bulimia. Physiology \& Behavior, 41, 621-626.

Drewnowski, A., Brunzell, J. D., Sande, K., Iverius, P. H., \& Greenwood, M. R. C. (1985). Sweet tooth reconsidered: Taste preferences in human obesity. Physiology \& Behavior, 35, 617622.

Drewnowski, A., Gosnell, B., Kiahn, D. D. \& Canum, K. (1989). Sensory preferences for sugar and fat: Evidence for opioid involvement. Appetite, 12, 206. (Abstract)

Drewnowski, A., \& Greenwood, M. R. C. (1983). Cream and sugar: Human preferences for high-fat foods. Physiology \& Behavior, 30, 629-633.

Drewnowski, A., Halmi, K. A., Pierce, B., Gibbs, J., \& Smith, G. P. (1987). Taste and eating disorders. American Journal of Clinical Nutrition, 46, 442-450.

Drewnowski, A., Pierce, B., \& Halmi, K. A. (1988). Fat aversion in eating disorders. Appetite, 10, 119-131.

Flatt, J. P., Ravussin, E., Acheson, K. J., \& Jequier, E. (1985). Effects of dietary fat on post-prandial substrate oxidation and on carbohydrate and fat balances. Journal of Clinical Investigation, 76, 1019-1024.

Garn, S. M., Solomon, M. A., \& Cole, P. E. (1980). Sugar-food intake of obese and lean adolescents. Ecology of Food \& Nutrition, 9, 219-222.

MatTES, R. D. (1985). Gustation as a determinant of ingestion: Methodological issues. American Journal of Clinical Nutrition, 41, 672-683.

Meiselman, H. L., Waterman, D., \& Symington, L. E. (1974). Armed forces food preferences (Tech. Rep. 75-63-FSL). Natick, MA: U.S. Army Natick Development Center.

Midkiff, E. E., \& BerNSTEIN, I. L. (1985). Targets of learned food aversions in humans. Physiology \& Behavior, 34, 839-841.

Morgan, K. J., Johnson, S. R., \& Stampley, G. L. (1983). Children's frequency of eating, total sugar intake and weight/height stature. Nutrition Research, 3, 635-652.

Moskowitz, H. R., Kluter, R. A., Westerling, J., \& Jacobs, H. L. (1974). Sugar sweetness and pleasantness: Evidence for different psychophysical laws. Science, 184, 583-585.

Paykel, E. S., Mueller, P. S., \& de la Vergne, P. M. (1973). Amitryptyline, weight gain and carbohydrate craving: A side effect. British Journal of Psychiatry, 125, 501-507.

Reed, D. R., Contreras, R. J., Maggio, C., Greenwood, M. R., \& RodIN, J. (1988). Weight cycling in female rats increases dietary fat selection and adiposity. Physiology \& Behavior, 42, 389 395 . 
Rosen, J. C., Leitenberg, H., Fisher, C., \& Khazam, C. (1986). Binge-eating episodes in bulimia nervosa: The amount and type of food consumed. International Journal of Eating Disorders, 5, 255267.

Rosenthal, N. E., Genhart, M., Jacobsen, F. M., Skwerer, R. G., \& WEHR, T. A. (1987). Disturbance of appetite and weight regulation in seasonal affective disorder. Annals of the New York Academy of Sciences, 499, 216-230.

RUSSELL, G. F. M. (1967). The nutritional disorder in anorexia nervosa. Journal of Psychosomatic Research, 11, 141-149.

Russell, G. F. M. (1979). Bulimia nervosa: An ominous variant of anorexia nervosa. Psychological Medicine, 9, 429-448.

Schwartz, R. S., Ravussin, E., Massari, M., O’Connell, M., \&
RobBins, D. C. (1985). The thermic effect of carbohydrate versus fat feeding in man. Metabolism, 34, 285-293.

Sclafani, A. (1985). Animal models of obesity. In R. T. Frankle, J. Dwyer, L. Moragne, \& A. Owen (Eds.), Dietary treatment and prevention of obesity (pp. 105-123). London: John Libbey.

The Surgeon General's report on nutrition and health (1988). (DHHS [PHS] Publ. No. 88-50210.) Washington, DC: U.S. Government Printing Office.

Tuorila, H., \& Pangborn, R. M. (1988). Prediction of reported consumption of selected fat-containing foods. Appetite, 11, 81-95.

WURTMAN, J. J. (1984). The involvement of brain serotonin in excessive carbohydrate snacking by obese carbohydrate cravers. Journal of the American Dietetic Association, 84, 1004-1007. 